\title{
Implementation of Family Planning for the Long Term Contraception Method (KB MKJP) Services in Palu City
}

\author{
Riyatno $^{1}$, Djayani Nurdin ${ }^{1}$, Nuraisyah Ambo ${ }^{1}$, Intam Kurnia ${ }^{1}$ \\ ${ }^{1}$ Doctoral Program in Social Sciences, Postgraduate, Tadulako University, Indonesia
}

\begin{abstract}
This study aims to analyze the implementation of the Family Planning for Long Term Contraception Method (KB MKJP) services in the City of Palu. The type of research used is descriptive with a qualitative approach by utilizing the post-positivism paradigm to see social phenomena that occur. Researchers determined the criteria for informants, namely program administrators, medical officers, and fertile age couples, including: 2 program administrators (BKKBN), 4 medical officers (Tadulako Hospital), 4 Fertile Age Couples (PUS). The results showed reliability with the aspect of timeliness, where the presence of medical personnel and program administrators was not according to what had been agreed or scheduled. Physical evidence with aspects of the facility, where the operating room is not yet available and does not meet the specified minimum requirements. Empathy with the information aspect, where the delivery of information related to KB MKJP in the form of risks and side effects is not conveyed to the PUS, while information in the form of Long-Term Contraceptive Method (MKJP) type of contraceptive methods, benefits, and benefits have been conveyed completely, clearly and easy to understand Fertile Age Couples (PUS). Empathy is seen from the information aspect that the information related to KB MKJP by program administrators and medical officers has been delivered completely and clearly. Responsiveness is not only seen by service providers, but can also be assessed through service recipients because in the selection of contraceptives there are still PUS who are not able to make appropriate decisions so that they require counseling or information delivery by program administrators.
\end{abstract}

Keywords: Public Services, Family Planning, Contraceptive Methods

Received: November 4, 2020

Received in Revised: November 14, 2020

Accepted: November 23, 2020

\section{Introduction}

Public services are closely related to the government because one of the responsibilities of the government is to provide services to the community. The public service paradigm requires the creation of quality public services and public participation to be dominant in order to achieve the goal of a welfare state which must substantially build an understanding to realize public services in accordance with the corridors of good governance (Bovaird, 2007; Holmes, 2011).

The quality of public services received by the community directly can be used as a benchmark in assessing government performance (Zafra-Gómez et al., 2009). Conceptually, service quality is a dynamic condition related to products, services, people, processes and the environment that meet or exceed expectations. Service quality is related to meeting customer expectations or needs. Zeithaml et al., 1988; Zhang \& Prybutok, 2005).

The quality of Family Planning for Long Term Contraception Method (KB MKJP) services services is carried out with the aim of helping PUS / acceptors to achieve individual health at an optimal level. Family planning services and reproductive health are how clients are treated by the available service system (Bruce, 1990). Therefore Zeithaml et al (1993) argued that service quality includes five dimensions, namely (1) reliability, namely the ability to deliver 
the promised services accurately; (2) Assurance, namely knowledge and politeness of workers and their ability to give trust to customers; (3) Tangible, namely the physical appearance of buildings, equipment, employees and other facilities owned by the providers; (4) Empathy, namely personal treatment or attention given by providers to the customer; (5) Responsiveness, namely the willingness to help customers and provide services sincerely (Parasuraman et al., 1985).

Service quality, the size is not only determined by the service provider (Provider) but more determined by the party served (PUS / acceptor), because they are the ones who enjoy the service so that they can measure the quality of service based on their expectations in fulfilling their satisfaction (Barata, 2004). This opinion is in line with Dwiyanto that assessing the performance of the public bureaucracy is not enough just to use the indicators inherent in the bureaucracy, such as efficiency and effectiveness, but also from the indicators attached to service users, such as service user satisfaction, accountability, and responsiveness (Dwiyanto at al, 2006).

The quality of family planning and health services has increasingly become the center of government attention. Improving the quality of service is seen as an alternative for improving the performance of the family planning program. Information on important aspects of service quality is not widely available to administrators and service providers. The low quality of service is a bad image of the government in the community and is an increasingly important issue in the development and health of family planning. Demands for the quality of the Family Planning Services for Long Term Contraception Method (KB MKJP) that are getting better cannot be avoided in line with the social economic improvement of the community. In order to strengthen and achieve the goal of MKJP family planning services, it is hoped that the organizers will be able to provide quality, rational, effective and efficient services and be able to increase the participatory prevalence rate (CPR) of KB MKJP. This study aims to analyze the implementation of the Family Planning Services for Long Term Contraception Method (KB MKJP) in the City of Palu.

\section{Methods}

The type of research used is descriptive with a qualitative approach by utilizing the postpositivism paradigm to see the social phenomena that occur. Researchers determined the criteria for informants, namely program administrators, medical officers, and fertile age couples, including: 2 program administrators (BKKBN), 4 medical officers (Tadulako Hospital), 4 Fertile Age Couples (PUS). Data collection techniques used were observation, interviews, and documentation. This study uses the data analysis technique used by the researcher is the analysis model of Miles \& Huberman (2002) which consists of three flows that take place simultaneously, namely data condensation, data presentation and drawing conclusions.

\section{Results and Discussion}

Based on the theory developed by Zeithaml at.al, that the quality of KB MKJP services is determined through five dimensions, namely reliability, assurance, tangible, empathy and responsiveness. The results and qualitative analysis of each of the dimensions of service quality can be described as follows:

\section{Reability}

The results of the research obtained on the reliability dimension indicate that in general the ability of the organizers to provide Family Planning Services for Long Term Contraception Method (KB MKJP) has not been as promised. This happens because the KB MKJP services 
that have been implemented are not on time. The inaccuracy is influenced by two unfulfilled factors, namely the attendance of the officer and the completion of the medical action process where the implementation has not been as promised so that it is said not to be on time. The presence of medical officers, in this case gynecologists and surgeons, is not according to the planned schedule or is not carried out as agreed so that it affects medical action at MKJP family planning services is often delayed. The inaccuracy of the presence of medical officers is of course caused by many things, including the results obtained from the interview with the informant, namely because obstetricians and surgeons are still in other hospitals to carry out their duties and responsibilities as a doctor to provide public services. In addition, the presence of BKKBN officers as program administrators was not according to the planned schedule or was not carried out as agreed, thus also affecting delayed medical action at Family Planning Services for Long Term Contraception Method (KB MKJP).

Likewise with the completion of the medical action process, that the RSU. Tadulako has not provided a certain time related to the completion of the medical action process so that the services provided by medical personnel are still relatively long for PUS. When service providers interact, PUS does not know exactly how long it will take to complete the medical treatment process for Family Planning Services for Long Term Contraception Method (KB MKJP). Time uncertainty is still attached to the practice of KB MKJP services. This occurs because there is no standard service time to regulate the completion of the medical action process and the standard time is not included in the Standard Operating Procedure (SOP) owned by the RSU. Tadulako as a guideline for the implementation of MKJP family planning services.

The unspecified standard time for completing the medical action process is of course not free from reasons such as those obtained from the interview results, namely because the medical staff in their actions exceeds the predetermined time so this shows that the service has not met the expectations of the EFA. Due to the absence of a standard time to complete the medical treatment process, this is very surprising because of the RSU. Tadulako is one of the government hospitals from an era that can be said to be very modern, civilized, can operate without having clear service standards and becomes a handle for service providers to PUS. The standard of service in the form of medical treatment process completion time is very basic and has long been common knowledge in public administration.

The importance of time standards has been reminded by Weber and his followers when they developed an ideal type of bureaucratic model, which in his thesis, Weber promoted his bureaucratic model, is that the ideal type of bureaucracy can create service certainty through the existence of written Standard Operating Procedures (Dwiyanto, 2015). Service time standards that are not included in the SOP can raise questions, namely why did this happen? Can the absence of a standard service time benefit the bureaucracy and its officers who carry out the MKJP family planning program because they can work at will in serving PUS? whatever the cause, such situations must end immediately.

PUS inconvenience related to MKJP family planning services should not continue. Certainty of service time must be created in order to establish good interpersonal relationships between service providers and PUS. Therefore, in providing quality services it is hoped that the BKKBN as the program organizer and the RSU. Tadulako as a medical officer should pay attention to the aspect of timeliness and determine the time standard as a measure and make it back as a guideline and included in the SOP owned by the RSU. Tadulako for the sake of increasing the achievement of Family Planning for Long Term Contraception Method (KB MKJP). Thus, we can think about what should be regulated in service standards. Service time standards are part of the government bureaucratic instrument. Therefore, service standards in 
the form of time standards need to be made without eliminating space for service providers to create and innovate.

The certainty of time for completing the medical action process becomes a barrier for service providers and PUS so that they interact with, easily, and respect each other's existence. By setting service time standards in a clear, simple manner, it is hoped that service providers will be able to properly implement these standards in their duties in order to improve service quality for the achievement of KB MKJP. The standard of service time is a guideline for the provider, while the PUS as a service user can ensure and control whether the services provided are as promised.

\section{Assurance}

In realizing its program to increase the achievement of KB MKJP, BKKBN is faced with various forms of guarantees in order to be able to foster trust in PUS. To gain this trust, the $\mathrm{BKKBN}$ as the program organizer continues to strive to improve service quality through a form of assurance that can encourage PUS to participate in using KB MKJP in the form of technical and security potential. The results of the research obtained through the guarantee dimension show that program administrators and medical officers in providing KB MKJP services are able to grow their trust in PUS. This trust is earned and built through the technical competencies of program administrators and medical officers, who in carrying out their duties provide KB MKJP services in accordance with guidelines or Standard Operating Procedures (SOP), and security where medical personnel can minimize the risk of infection and side effects that can be cause inconvenience to EFA in connection with the services provided.

Security shows that in carrying out their duties, medical personnel can minimize the risk of infection and side effects caused by the type of MKJP used by PUS. The ability of medical personnel to minimize the risk of infection and side effects is supported by adequate knowledge so as to reduce the risk of infection and side effects. In relation to KB MKJP, there are two types of MKJP that have side effects, namely IUDs and implants. IUD contraceptives have side effects in the form of heavy bleeding when the menstrual period arrives, changes in the menstrual cycle, when there is more menstruation and the time is longer. While the side effects of implant contraceptives can include spotting bleeding, headaches, dizziness, weight gain / loss, breast pain, and nausea.

The side effects that have been described are complaints and cause anxiety which is often felt by PUS. However, overcoming the complaint, the medical officer conducted another counseling in order to relieve anxiety and convince PUS that the type of MKJP that had been used was still safe. Apart from providing counseling, medical officers have also provided and provided ibuprofen as an anti-pain medication so that complaints are felt by PUS. However, the risk of infection was only felt by PUS as Mantap contraceptive users, namely MOW and MOP. Infection that occurs can be in the form of injury to the area of surgery or surgery. To overcome the infection that occurs, medical personnel also provide and provide antibiotic salves as drugs to minimize the risks that occur. Therefore, in providing quality KB MKJP services, it is hoped that the ability of medical personnel to be able to minimize the risk of infection and side effects caused by the use of FP MKJP by PUS as far as possible increases the achievement of KB MKJP.

\section{Tangible}

As is well known, the quality of service is also very much determined by physical evidence (tangible). Therefore, service providers must provide physical evidence, namely service facilities and infrastructure that can be seen clearly and utilized by program administrators 
and medical officers and can be felt by PUS participating in the KB MKJP program. The results obtained through the dimensions of physical evidence that the facilities and infrastructure owned by the hospital. Tadulako is still adequate and can be properly functioned and used by medical officers in providing MKJP family planning services. The facilities and infrastructure in question include physical facilities, in the form of waiting rooms, service rooms, as well as operating rooms and equipment for service procedures, in the form of medical equipment.

The physical facilities in the form of a waiting room owned by Tadulako Hospital are still suitable for use. The waiting room is a form of physical facility that benefits significantly and functions as a room for waiting their turn by the PUS in order to receive KB MKJP services. Quality is conformance to requirement, which is in accordance with the requirements or standards. Thus, the available waiting room must meet the Minimum Service Standards (SPM) of the hospital, namely having a room that is quite spacious, clean, and has supporting facilities in the form of a fan, a long chair for PUS, and the availability of a toilet so that it can provide comfort for PUS.

Apart from physical facilities, KB MKJP services are said to be of quality if they have complete service procedures, namely in the form of medical equipment. The results of the interviews were obtained through informants that the medical equipment owned by the RSU. Tadulako is sufficient. The completeness of the medical equipment is used for the purposes of the medical treatment process in KB MKJP services and at the same time as a support for the smoothness of the medical process. Medical equipment in KB MKJP services has various types of equipment. Each of the medical equipment in question is in the form of scales, tensimeters, IUD contraceptives, implants, syringes, local anesthetics, and Mantap contraceptive medical equipment. In addition, there is also an emergency kit prepared by medical personnel for patients in an emergency, namely in the form of oxygen, intravenous equipment along with fluids and is equipped with medicines. Medical equipment is the absolute responsibility of medical officers to always control their completeness so that medical equipment spare parts are still available every time they perform services.

In an advanced society with sophisticated equipment, activities in human life are increasingly dependent on the existence of equipment, even if only partially. Realizing this, the completeness of service procedures in the form of existing medical equipment must always be maintained in accordance with the standards, procedures and methods of use in order to provide optimal results in carrying out KB MKJP service activities. Medical equipment that is not properly maintained, can affect service activities to be fatal. For example work equipment that is driven by electricity. Today, the life of modern society, both in the business community, and in the household, depends a lot on various work tools that are powered by electricity. All work equipment in the form of machines in an agency or organization are driven and controlled by electricity. If there is a disturbance in the electrical system, it will cause the work equipment to malfunction and delay activities.

The forms of facilities and infrastructure that have been described are one of the forms of service quality in order to improve the achievement of KB MKJP, besides that they are also part of work performance which is one of the considerations in organizational management. Arisutha (2005) states that work performance is shown by individual human resources, and becomes an assessment in applying work activities which can be assessed from the form of physical facilities and infrastructure. The quality of service provided by the hospital medical staff. Tadulako is important and the main thing in improving the achievement of KB MKJP, therefore PUS who receive services can assess the condition and physical infrastructure seen 
and can be used directly from service providers either using, operating and addressing the conditions of physical infrastructure in providing a service.

\section{Empathy}

The KB MKJP service provided by program administrators and medical officers to PUS as being served requires empathy (empathy) so that what is BKKBN's goal, namely increasing the achievement of KB MKJP can be achieved. Quality KB MKJP services require personal attention to all forms of management related to MKJP family planning services as well as being able to understand what the EFA needs. In other words, the empathy of program administrators and medical staff must be able to understand EFA with full attention. Thus, the results of research through interviews with informants show that program administrators and medical officers in carrying out their duties do not pay attention (empathy) to what EFA needs and this is influenced by two aspects, namely information and sustainability.

As already explained that in providing MKJP family planning services, program administrators and medical officers must convey information clearly, completely and easily understood by PUS in relation to KB MKJP. Information is "counseling", namely face-toface communication carried out by program administrators and medical officers to assist PUS in carrying out decisions in choosing the type of KB MKJP to be used, therefore the elements contained in the information must be clear, complete and easy to understand as already submitted to the PUS. In order for the provision of counseling to run smoothly, program administrators and medical officers must treat or serve each PUS well, namely by being patient, respecting each EFA, and maintaining the trustworthiness of PUS in the confidentiality related to the use of contraceptives; avoid providing excessive information; as well as interacting with the PUS, namely the officers listening, studying and giving good responses to the PUS.

In general, the purpose of contraceptive counseling is to improve the quality of MKJP family planning services so that program administrators and medical officers can assist PUS in determining or choosing the type of KB MKJP to be used (informed choice) according to their choice. However, specifically the purpose of the counseling is to provide information clearly, completely and easily understood by the PUS. Apart from general and specific purposes, counseling and information also aim to identify and accommodate feelings of doubt and anxiety experienced by PUS in connection with services, use of MKJP tools, so that program administrators and medical staff can provide assistance; help select the type of MKJP that is the best, safe, and in accordance with the conditions and wishes of the EFA; provides information on various types of MKJP tools.

The results showed that several informants stated that socialization was also a form of information which was implemented openly to all levels of society. In its program, the BKKBN is still lacking in socializing the KB MKJP so that many people have not received information regarding the KB MKJP. The achievement of KB MKJP can increase if the socialization activities are increased to all levels of society in question and conduct Communication, Information, Education (IEC) activities to increase knowledge of EFA because considering the low understanding of PUS in responding to the information that has been conveyed. Niken (2010) states that IEC activities are a step that should not be abandoned, IEC is also the key in family planning services, especially in MKJP family planning services.

Sustainability is also a form of quality service. Continuity of service is a follow-up to an activity of KB MKJP services. The follow-up referred to is in the form of post-action follow- 
up examinations on the use of KB MKJP by medical officers. In this sense, the PUS must get follow-up service and know the time of control to get the intended follow-up service. continuity or follow-up is carried out aiming to determine the development of the use of KB MKJP. Thus, the research results indicate that continuity or follow-up services have not been implemented properly. According to the results of interviews obtained from several informants, it was stated that in general, post-action follow-up examinations by medical personnel were not carried out. Post-action follow-up examinations were not carried out because medical staff only served PUS who had complaints or side effects caused by the use of contraceptives used by PUS. After the PUS action, there are no complaints or side effects, so the medical staff only prepares and provides anti-pain medication to anticipate if one day there are complaints or side effects felt by PUS for using KB MKJP. However, the follow-up examination is a service that needs to be done again in order to control the development of the use of KB MKJP so that complaints or side effects occur early on.

\section{Responsiveness}

As already explained, responsiveness is the attitude of program administrators and medical officers to assist and respond to each PUS participating in the MKJP family planning program by providing appropriate services. Thus, the quality of KB MKJP services is influenced by the accuracy of service, which is a form of responsiveness that the program administrators and medical officers have. MKJP family planning services are said to be appropriate if the services are provided according to the wishes of the PUS. Therefore, program administrators and medical staff must pay attention to their attitudes so that the selection of contraceptives is given precisely as desired by PUS in order to increase the achievement of KB MKJP.

Through interviews with informants, the program administrators and medical officers in carrying out their duties have a responsive attitude and are able to provide appropriate services. The services provided have met exactly the needs of the PUS, where the selection of contraceptives is given by the program administrators and medical officers according to the choice of PUS. Contraceptives provided and offered by program administrators and medical personnel include the IUD / IUD, AKBK / Implant, MOW, and MOP. Of the several types of family planning available, IUD / IUD and implant are the most dominant contraceptives in demand by PUS because IUD contraceptives have a fairly high effectiveness, namely 8 to 10 years and AKBK, namely 3 to 5 years of use.

In addition, MOW and MOP are steady contraceptives which have a higher effectiveness than IUD or implant, which are lifelong and permanent for MOW contraception. This method requires consideration because of the permanent nature of MOW contraception so that PUS does not regret it in the future. Therefore, the selection of the Mantap contraception is only intended for PUS who do not want to have children anymore and fulfill the voluntary, healthy and happy requirements. The choice of contraceptives by PUS is part of the accuracy of services provided by program administrators and medical officers.

The choice of contraceptives given according to the wishes of PUS is a form of service and is a positive respect for the responsiveness of program administrators and medical officers in an effort to improve the achievement of KB MKJP. Thus, EFAs who get a good response will be satisfied with the services they receive. However, if the services obtained are otherwise, then the service shows a lack of responsiveness (responsiveness) that is owned by program administrators and medical personnel. Apart from that, the responsiveness of PUS is also different from that of others, because the services provided are adjusted to the level of responsiveness of each PUS who will receive contraception as their choice in the family planning program. 
Responsiveness is not only seen in service providers, but can also be assessed through service recipients because in the selection of contraceptives there are still PUS who have not been able to make the right decisions so that it requires counseling or information delivery by program administrators and medical staff wisely, clearly, and completely., transparent, concise, easy to understand and accountable so that the PUS can understand what is being said regarding the choice of contraceptives and is responsive to the information it receives. Counseling that is able to be implemented properly, it can be said that program administrators and medical officers have responsive skills that make a KB MKJP service run optimally.

\section{Conclusion}

Reliability is seen from the aspect of timeliness, that the presence of medical personnel and program administrators is not yet as agreed or scheduled. So it is with the completion of the action process. The guarantee is seen from the technical competency aspect, that the procedures governing the stages of completion of the service process by program administrators and medical personnel are in accordance with Standard Operating Procedures (SOP). Physical evidence shows that the operating room does not meet the minimum requirements specified. However, contraceptive services for the Female Operation Method (MOW) and the Male Operation Method (MOP) are still carried out as planned through adequate, affordable, and competent service facilities. Meanwhile, from the aspect of completeness of medical equipment, that the medical equipment owned by the hospital. Tadulako is still quite adequate. This is evidenced by the availability of medical devices in the form of scales, tensimeters, intrauterine device (IUD) contraceptives, implants, syringes, local anesthetics, medical devices for surgery, and emergency equipment in the form of oxygen, intravenous devices and medicines. Empathy is seen from the information aspect that the information related to KB MKJP by program administrators and medical officers has been delivered completely and clearly, but the information that has been submitted cannot be understood by the PUS. Responsiveness is seen from the aspect of accuracy of service, where the selection of contraceptives is provided by program administrators and medical personnel according to the choice or desire of PUS.

\section{References}

Arisutha, D. (2005). Dimensi Kualitas Pelayanan. Jakarta: Penerbit Gramedia Pustaka.

Barata, A. A. (2003). Dasar-dasar pelayanan prima. Elex Media Komputindo.

Bovaird, T. (2007). Beyond engagement and participation: User and community coproduction of public services. Public administration review, 67(5), 846-860.

Bruce, J. (1990). Fundamental elements of the quality of care: a simple framework. Studies in family planning, 21(2), 61-91.

Dwiyanto, A. (2006). Mewujudkan Good Governence melalui Pelayanan Public, Yogyakarta. UGM Press.

Dwiyanto, A. (2015). Manajemen Pelayanan Publik, Inklusif, dan Kolaborasi. Yogyakarta: Gajamada Universitas Perss.

Holmes, B. (2011). Citizens' engagement in policymaking and the design of public services. Canberra: Parliamentary Library.

Huberman, M., \& Miles, M. B. (2002). The qualitative researcher's companion. Sage.

Niken. (2010). Pelayanan Keluarga Berencana. Yogyakarta: Fitramaya. 
Parasuraman, A., Zeithaml, V. A., \& Berry, L. L. (1985). A conceptual model of service quality and its implications for future research. Journal of marketing, 49(4), 41-50.

Zafra-Gómez, J. L., López-Hernández, A. M., \& Hernández-Bastida, A. (2009). Evaluating financial performance in local government: maximizing the benchmarking value. International Review of Administrative Sciences, 75(1), 151-167.

Zeithaml, V. A., Berry, L. L., \& Parasuraman, A. (1988). Communication and control processes in the delivery of service quality. Journal of marketing, 52(2), 35-48.

Zeithaml, V. A., Berry, L. L., \& Parasuraman, A. (1993). The nature and determinants of customer expectations of service. Journal of the academy of Marketing Science, 21(1), 1-12.

Zhang, X., \& Prybutok, V. R. (2005). A consumer perspective of e-service quality. IEEE transactions on Engineering Management, 52(4), 461-477. 